\title{
Phenotypic characterization of antimicrobial drug resistance of Staphylococcus aureus and S. epidermidis strains isolated from various community infections in Oum El Bouaghi city, Algeria
}

\author{
AMINA RAHMANI", LAAREM MERADI, KARIMA MALAWI, FATMA KHANFOUF \\ Department of Natural and Life Sciences, Laboratory of Biotechnology of Natural Substances and Applications Larbi-Ben-M'hidi University of Oum El \\ Bouaghi 040000, Algeria, Tel.: +213-542898529, `email: aminarahmani311@gmail.com
}

Manuscript received: 16 February 2021. Revision accepted: 19 April 2021.

\begin{abstract}
Rahmani A, Meradi L, Malawi K, Khanfouf F. 2021. Phenotypic characterization of antimicrobial drug resistance of Staphylococcus aureus and S. epidermidis strains isolated from various community infections in Oum El Bouaghi city, Algeria. Biodiversitas 22: 2665-2671. In Algeria most community infections caused by Staphylococcus epidermidis and Staphylococcus aureus present resistance to several antibiotics and induce therapeutic failures. The aim of this study is the characterization and the comparison of antimicrobial resistance of Staphylococcus strains isolated from community infection in Oum El Bouaghi city, Algeria. Species identification was realized by conventional biochemical tests and the determination of antibiotics susceptibility pattern was realized by using the agar disk diffusion method, according to the recommendations of the French Society for Microbiology (FSM, 2019). A total of 102 Staphylococci strains were obtained from clinical samples, with a frequency of isolation of $57,8 \%$ for $S$. epidermidis and $42,2 \%$ for $S$. aureus, both strains present a resistance for most used antibiotics, the higher resistance was found for oxacillin in both strains with 25,6\% for S. aureus and 42,4\% for S. epidermidis. Multidrug-Resistance (MDR) phenotype was detected in 37,3\% of S. epidermidis and $14 \%$ in $S$. aureus strains. In Algeria, new control policies should be adopted to prevent the further spread of antimicrobial-resistant strains, especially in the community.
\end{abstract}

Keywords: Antimicrobial resistance, community-infection, MDR, Staphylococcus aureus, S. epidermidis

\section{INTRODUCTION}

Overuse of antibiotics in human medicine is the contributor of the apparition of antimicrobial resistance, it's now recognized as a global health problem and has enormous economic and health impacts ( $\mathrm{Li}$ and Webster 2018) and has led to the emergence of resistant bacterial strains (Safarpoor et al. 2017). Staphylococcus isolates are opportunistic facultative pathogens widely distributed worldwide, ubiquitous, found as normal flora of the skin, nasopharynx, anterior nares, and mucous membranes of humans (Ceballos et al. 2019) and also in several environments. Based on their coagulase plasma, staphylococci is divided into two main groups, coagulasepositive Staphylococci (CoPS) include Staphylococcus aureus and the coagulase-negative Staphylococci (CoNS) (more than 30 species) such as: Staphylococcus haemolyticus and S. epidermidis (Becker et al. 2014).

The increasing prevalence of antimicrobial-resistant $S$. aureus has received much attention, in recent decades (Castro et al. 2016), it constitutes a serious public health problem because of its high colonizing and infectious capacity to cause a wide variety of suppurative infections in humans (Bassetti et al. 2017). Diseases caused by $S$. aureus depend on the host's immunity, age, normal flora and drug consumption (Kandi 2018). Nearly $30 \%$ of the human population is asymptomatically colonized with $S$. aureus (Saleem et al. 2018). The CoNS were considered harmless skin commensal bacteria prior to the 1970s
(Contreras et al. 2003) but in recent years, CoNS have been recognized as important opportunistic pathogens including: Staphylococcus epidermidis, S. saprophyticus, S. haemolyticus, and S. bugdunensis (Becker et al. 2014). While traditionally, CoNS considered as less pathogen than CoPS (Fišarová et al. 2019). The dissemination of multidrug resistance in Staphylococcus spp. (Virdis et al. 2010) and Methicillin-resistant S. aureus (MRSA) is a serious health concern (Castro et al. 2016). It has acquired resistance to several families of antibiotics, often detected in hospitals and communities (John et al. 2019). The evaluation of the antimicrobial susceptibility of Staphylococcus spp. isolates determine which antibiotics should be administrated for monitoring the spread of resistant strains in community (Morency-Potvin et al. 2017).

In Algeria antimicrobial resistance, especially in $S$. aureus, represents one of the most important human healththreatening, in addition, investigations on the resistant patterns of $S$. epidermidis are very limited, for these reasons the aim of this study is to determine phenotypic characterization of antimicrobial drug resistance of $S$. aureus and $S$. epidermidis strains isolated from various community infections in Oum El Bouaghi city, Algeria.

\section{MATERIAL AND METHODS}

\section{Sources of clinical samples}

The investigation of Staphylococcus strains included 980 clinical samples, during January-October 2020 in Oum 
El Bouaghi (Algeria). A total of 102 strains were isolated from many pathological samples (blood, pus, vaginal swab, sperm culture, skin sample, urine, breast sampling, and vulvar puncture) in the community medical analysis laboratory at Oum El Bouaghi (Algeria). All samples were transported to the laboratory in iceboxes at $4{ }^{\circ} \mathrm{C}$ and were analyzed within 1 to 2 hours after sampling.

\section{Microbiological isolation and identifications}

To isolate strains, clinical samples were cultured $24 \mathrm{H}$ on Mannitol salt-agar (Chapman Agar) at $37^{\circ} \mathrm{C}$. Isolates were grown and confirmed after culture as Staphylococcus aureus and $S$. epidermidis by microscopic characters such as bacterial morphology, mobility, Gram-stain and biochemical tests: catalase, oxidase, coagulase, hemolysis, DNase, mannitol fermentation tests (Quinn et al. 1994), and API STAPH-IDENT System (Wesley et al. 1982).

\section{Antibiotic susceptibility tests}

A total of 102 isolates were tested, after $24 \mathrm{H}$ at $37^{\circ} \mathrm{C}$ of incubation, and antibiotic susceptibility testing was performed using the standard disk diffusion method according to the recommendations of the Antibiogram Committee of the French Microbiology Society (http://www.sfm-microbiologie.org/). From each isolate, bacterial inoculums ( 0,5 Mac Farland) were swabbed on Muller-Hinton agar.

The 12 drugs tested and their concentrations are cefoxitin $(30 \mu \mathrm{g})$, oxacillin $(1 \mu \mathrm{g})$, imipenem $(10 \mu \mathrm{g})$, vancomycin $(30 \mu \mathrm{g})$, ciprofloxacin $(5 \mu \mathrm{g})$, gentamycin $(10 \mu \mathrm{g})$, cotrimoxazole $(25 \mu \mathrm{g})$, erythromycin $(15 \mu \mathrm{g})$, lincomycin $(2 \mu \mathrm{g})$, spiramycin $(15 \mu \mathrm{g})$, pristinamycine $(15 \mu \mathrm{g})$ and fosfomycin $(200 \mu \mathrm{g})$. The plates were incubated at $37^{\circ} \mathrm{C}$ for $24 \mathrm{H}$. The zone of growth inhibition around antibiotic discs was evaluated according to FSM (2019). Isolates were designated as resistant, sensitive, or inter-mediate after the measured zone of inhibition around antibiotic discs according to FSM (2019). The isolates were distinguished as MRSA (Methicillin-resistant Staphylococcus aureus) and MSSA (Methicillin sensitive Staphylococcus aureus) respectively by Oxacillin Disk Diffusion Method, and strains exhibiting resistance to three or more classes of antibiotics were defined as multidrug-resistant (MDR).

\section{Statistical analysis}

The data analysis was done using SPSS version 20, and Values were expressed as the percentages of the variables. In order to evaluate the difference in antibiotic resistance of the clinical strains obtained ( $S$. aureus and $S$. epidermidis) the Pearson's Chi-square $\left(X^{2}\right)$ test was performed, with 95\% as confidence intervals, so a $P$-value less than $5 \%$ were considered statistically significant.

\section{RESULTS AND DISCUSSION}

Staphylococcus aureus is a gram-positive bacterium that has a greater impact on human health by causing various diseases (Mahendra et al. 2020). In this study, a total of 102 Staphylococcus isolates obtained from 980 samples were identified giving an overall prevalence of
$10.4 \%(102 / 980)$ which is almost similar to the results of a study by Gahamanyi et al. (2017) in Rwanda with a prevalence of $10 \%$, but lower than that observed in Nigeria $(24.5 \%)$ (Chijioke et al. 2016). Among the 102 Staphylococcus infections, the prevalence of $S$. aureus was $42.2 \%$, which is higher than the rate obtained in Algeriers $38 \%$ (Antri et al. 2011) and in Eastern Algeria 19.6\% (Alioua et al. 2014). S. epidermidis is the most commonly reported CoNS species implicated in infections (Asante et al. 2020; Zatout et al. 2020). In worldwide, the prevalence of $S$. epidermidis in human infections varied from $6 \%$ to $68 \%$ (Asante et al. 2020), in this study this prevalence presents a rate of $57.8 \%$, which is higher than that found in another study conducted in Algeria 43.9\% (Zatout et al. 2020), in Iran 46\% (Chabi and Momtaz 2019), and in Nigeria $1.1 \%$ (Shittu et al. 2012).

Data of Table 1 showed that $S$. epidermidis is more frequently isolated from infections than $S$. aureus, as demonstrated by other studies (Oliveira et al. 2017), this high occurrence of $S$. epidermidis is may be due to the presence of various virulence factors which can be considered as the main reasons to cause infections (Otto 2009), and probably persistent carriage of this germ could act as a reservoir for infection (Archana et al. 2014), contrary to other results obtained in several countries showing that $S$. aureus is more frequent than $S$. epidermidis such as in Nigeria (Shittu et al. 2012) and in China (Yang et al. 2020).

Staphylococcus aureus is one of the most common causes of infections and it's also a normal flora of skin that can enter the body through abrasion, cracks, burn, surgical incisions, cuts and causes pyogenic infections (Sangita et al. 2019). This study has revealed that $S$. aureus is the most predominant micro-organism from pus samples, as earlier studies have indicated (Onemu and Ophori 2013), with the occurrence of $72.7 \%$ which is almost similar to the finding in the study conducted in Algeria 64.28\% (Benyagoub et al. 2020), but its higher than results obtained in Egypt $38 \%$ (Abdeen et al. 2021) and in Maroc 19\% (Benouda and Elhamzaui 2009). For $S$. epidermidis the highest occurrence was identified from urine with the rate of $91.4 \%$, probably this is primarily related to the contamination of urine by the commensal flora (Frédéric et al. 2008), and according to Longauerova (2006) CoNS have emerged as a principal cause of UTIs, especially $S$. epidermidis (Nanoukon et al. 2017).

Table 1. Staphylococcus aureus and S. epidermidis prevalence according to samples types

\begin{tabular}{lccc}
\hline Samples & $\begin{array}{c}\text { Prevalence of } \\
\text { Staphylococcus } \\
\text { strains according } \\
\text { origin n (\%) }\end{array}$ & $\begin{array}{c}\text { S. aureus } \\
\text { prevalence } \\
\mathbf{n}(\%)\end{array}$ & $\begin{array}{c}\text { S. epidermidis } \\
\text { prevalence } \\
\mathbf{n}(\%)\end{array}$ \\
\hline Urine & $35(34.3 \%)$ & $3(8.6 \%)$ & $32(91.4 \%)$ \\
Skin & $1(1 \%)$ & $0(0 \%)$ & $1(100 \%)$ \\
Vaginal & $3(3 \%)$ & $0(0 \%)$ & $3(100 \%)$ \\
Pus & $44(43.1 \%)$ & $32(72.7 \%)$ & $12(27.3 \%)$ \\
Mammary & $8(7.8 \%)$ & $2(25 \%)$ & $6(75 \%)$ \\
Sperm culture & $9(8.8 \%)$ & $5(55.6 \%)$ & $4(44.4 \%)$ \\
Blood & $1(1 \%)$ & $1(100 \%)$ & $0(0 \%)$ \\
Vulvar & $1(1 \%)$ & $0(0 \%)$ & $1(100 \%)$ \\
Total & 102 & $43(42.2 \%)$ & $59(57.8 \%)$ \\
\hline
\end{tabular}


Data in Table 2 show the variation of the prevalence of $S$. epidermidis and $S$. aureus according to the gender of patients. According to the Chi-square test, there is a significant difference in the distribution of $S$. epidermidis and $S$. aureus between males and females ( $p$-value $<0.05$ ). The rate of isolation in $S$. epidermidis is higher in females $(66.1 \%)$ than in males $(33.9 \%)$, contrary to $S$. aureus which is more frequent in males $(55.8 \%)$ than in females $(44.2 \%)$, according to a study by Gahamanyi et al. (2017) in Rwanda males $(63.3 \%)$ had more S. aureus than females $(36.7 \%)$. The Chi-square test shows that there is no difference between the two strains at each age group ( $p$-value $>0.05$ ) (Table 3). The highest isolation rate of $S$. aureus and $S$. epidermidis are in the age category between 30-59 years old. The result for $S$. aureus is also in agreement with another Algerian study (Benyagoub et al. 2020), probably the factors associated with colonization by $S$. aureus were age group (Archana et al. 2014).

Overuse and misuse of antibiotics in clinical setups have led to the emergence of resistance in bacteria ( $\mathrm{Ji}$ et al. 2018) in the community. Much less is known about the epidemiology of CoNs in health care facilities compared to MRSA (methicillin-resistant Staphylococcus aureus) (Becker et al. 2014). Methicillin resistance among Staphylococci is may be due to the expression of the mecA gene (Zong et al. 2011). This study provides important data on methicillin resistance, we found $68 \%$ the rate of resistance of methicillin (oxacillin), including $42.4 \%$ in S. epidermidis and $25.6 \%$ in $S$. aureus, the rate of MRSA is higher than that shown by Alioua et al. (2014) in Algeria (7.6\%), but its lower than the rate observed in another study in Algeria 40.5\% (Antri et al. 2010), and as reported by the World Health Organization (WHO) that in some African regions, $80 \%$ of S. aureus and S. spp infections are methicillinresistant (Kaasch et al. 2014). In developed countries, the prevalence of MRSA has reached a disturbing level within the past few years (Altaf et al. 2019).
Based on the antimicrobial susceptibility patterns thirty two Staphylococcus strains were MSSA (Table 4), most of MSSA isolates were susceptible to nearly all antimicrobial agents used in this study, in contrast, for the MRSA strains, the most prevalent resistances were for cefoxitin and oxacillin $(25.6 \%)$ respectively, others studies showed that the resistance to $\beta$-lactam is more than $50 \%$ in $S$. aureus strains (John et al. 2019). Among the MRSA obtained, one strain $(9.1 \%)$ presents resistance to lincosamides associated with macrolides susceptibility $\left(E R Y^{S}{ }_{-} L^{R}{ }^{R}\right.$ phenotype) which is more frequent among MRSA isolates of animal origin but is very unusual among MRSA of human origin (Schwarz et al. 2018). We found only $2.3 \%$ of MRSA are resistant to imipenem and $11.6 \%$ were resistant to fluoroquinolones and lincosamides this resistance is probably due to the use of these antibiotics to treat several community infections caused by S. aureus (Massanari et al. 1988), thus this resistance may induce clinical failure as has been reported by Siberry et al. (2003). But these resistance rates are lower than the results obtained in the study conducted by Ceballos et al. (2019) in Spanish hospitals which indicates that resistance to fluoroquinolones is $67 \%$ and $50 \%$ for lincosamides. The antibiotic resistance pattern of MRSA showed lower resistance rates to some family of antibiotics including aminoglycosides (4.7\%), antifolates (11.6\%), and macrolide (20.9\%) compared to results of a previous study in Algeria (Achek et al. 2018).

Table 2. Distribution of Staphylococcus aureus and $S$. epidermidis according to gender

\begin{tabular}{llll}
\hline Sex & S. epidermidis & S. aureus & p-value \\
\hline Male & $20(33.9 \%)$ & $24(55.8 \%)$ & 0.027 \\
Femal & $39(66.1 \%)$ & $19(44.2 \%)$ & 0.027 \\
\hline
\end{tabular}

Table 3. Distribution of Staphylococcus aureus and S. epidermidis according to age groups

\begin{tabular}{lllll}
\hline Organisms & $\mathbf{1 1 4}$ years & $\mathbf{1 5 - 2 9}$ years & $\mathbf{3 0 - 5 9}$ years & $\geq \mathbf{6 0}$ years \\
\hline Staphylococcus aureus & $2(33.3 \%)$ & $7(38.9 \%)$ & $19(45.2 \%)$ & $15(41.7 \%)$ \\
Staphylococcus epidermidis & $4(66.7 \%)$ & $11(61.1 \%)$ & $23(54.8 \%)$ & $21(58.3 \%)$ \\
p-value & 0.652 & 0.757 & 0.598 & 0.941 \\
\hline
\end{tabular}

Table 4. Comparison of antibiotic susceptibility pattern of Staphylococcus aureus and S. epidermidis using the Chi-square test

\begin{tabular}{|c|c|c|c|c|}
\hline \multirow{2}{*}{ Antibiotics } & \multicolumn{2}{|c|}{ Staphylococcus aureus $(\mathrm{n}=43)$} & \multirow{2}{*}{$\begin{array}{c}\text { Staphylococcus epidermidis } \\
(\mathrm{n}=59)\end{array}$} & \multirow{2}{*}{$p$-value } \\
\hline & $\operatorname{MSSA}(\mathbf{n}=32)$ & MRSA (n=11) & & \\
\hline Cefoxitin & $32(74.4 \%)$ & $11(25.6 \%)$ & $25(42.4 \%)$ & 0.080 \\
\hline Oxacillin & $32(74.4 \%)$ & $11(25.6 \%)$ & $25(42.4 \%)$ & 0.080 \\
\hline Imipenem & $42(97.7 \%)$ & $1(2.3 \%)$ & $0(0 \%)$ & 0.000 \\
\hline Vancomycin & $43(100 \%)$ & $0(0 \%)$ & $0(0 \%)$ &.$^{\mathrm{a}}$ \\
\hline Ciprofloxacin & $38(88.4 \%)$ & $5(11.6 \%)$ & $11(18.6 \%)$ & 0.336 \\
\hline Gentamicin & $41(95.3 \%)$ & $2(4.7 \%)$ & $13(22.0 \%)$ & 0.014 \\
\hline Cotrimoxazole & $38(88.4 \%)$ & $5(11.6 \%)$ & $21(35.6 \%)$ & 0.006 \\
\hline Erythromycin & $34(79.1 \%)$ & $9(20.9 \%)$ & $19(32.2 \%)$ & 0.208 \\
\hline Lincomycin & $38(88.4 \%)$ & $5(11.6 \%)$ & $16(27.1 \%)$ & 0.056 \\
\hline Spiramycin & $40(93.0 \%)$ & $3(7 \%)$ & $11(18.6 \%)$ & 0.091 \\
\hline Pristinamycin & $40(93.0 \%)$ & $3(7 \%)$ & $6(10.2 \%)$ & 0.575 \\
\hline Fosfomycin & $39(90.7 \%)$ & $4(9.3 \%)$ & $9(15.3 \%)$ & 0.373 \\
\hline
\end{tabular}

Note: MSSA: Methicillin Sensitive Staphylococcus aureus, MRSA: Methicillin-resistant Staphylococcus aureus,p-value $<0.05=$ significant 
The finding of multiple antimicrobial resistance in CoNs is alarming (Nascimento et al. 2015). Data in Table 4 shows that in S. epidermidis, the highest resistance is being to both oxacillin and cefoxitin (42.4\%), this work demonstrated that resistance to aminoglycosides is to $22 \%$, macrolides $(32.2 \%)$, and antifolates $(35.6 \%)$. Our results are higher than those found by Achek et al. (2018). According to literature, aminoglycoside resistance is also frequent in Staphylococcal species (Nemeghaire et al. 2014), these species can harbored aacA-D gene-encoded resistance to aminoglycosides, which is more prevalent and diffused in staphylococci of human origin (Johler et al. 2011), and probably the strains may express enzymes mediating gentamicin resistance, such as gentamicin phosphotransferase and aminoglycoside 60-N-acetyltransferase (Eladli et al. 2019). S. epidermidis strains have acquired resistance to other antibiotics such as rifamycin, fluoroquinolones, gentamicin, tetracycline, chloramphenicol, erythromycin, clindamycin, sulfonamides, and streptogramins because the overuse of antibiotics has led to the emergence of infectious bacteria resistant to a wide antimicrobial agent (Otto 2009; Rogers et al. 2009).

None of the strains has presented resistance to vancomycin, which is widely accepted as the most effective drug to treat staphylococcal infections (Holmes and Jorgensen 2008). Gentamicin, imipenem, and cotrimoxazole have preserved their activities; this is probably due to the low use of these antibiotics only in cases of severe infections caused by MDR organisms in human medicine (Kellie et al. 2019). The Chi-square test has indicated that there is no significant difference in resistance rates to all antibiotics used ( $p$-value $>0,05)$ between $S$. aureus and $S$. epidermidis, except for imipenem, gentamicin, and cotrimoxazole ( $p$-value $<0.05)$, these findings suggest that both strains can harbor antibiotic resistance genes but not expressing theses genes (Martineau et al. 2000; Duran et al. 2012). Overall, we found in this study that $22 \%$ of $S$. epidermidis were resistant to gentamicin compared to $S$. aureus with $4,7 \%$. These observations are also in agreement with the findings of Martineau et al. (2000). Resistance to aminoglycosides such as gentamicin has increasingly been reported in CoNS species (Dubin et al. 1999).

Data of Tables 5, 6, and 7 delivers important information on current antimicrobial resistance, including multi-drug resistance (MDR) and Methicillin-Resistance (MR) for a collection of clinical isolates of $S$. aureus and $S$. epidermidis from community infections. It is alarming to have a high rate of MDR Staphylococcus in the community, especially in S. epidermidis, which is one of the CoNs recognized as a cause of nosocomial infections (Becker et al. 2014). Both strains present resistance between 3 to 7 different families of antibiotics (Table 6). However, the resistance mechanisms in CoNs are less well defined (Srinivasan et al. 2002), but multiresistant $S$. epidermidis is a potential source for transferring the mec gene and several genes encoding resistance to antibiotics between pathogenic Staphylococcal species (Shittu et al. 2012). So, this multi-resistance in developing countries is may be due to the not controlled use of antibiotics because several antibiotics are available without a doctor's prescription (Kakai and Wamola 2002). The rise of resistance phenotype can be associated with automedication without prescription, lack of awareness in most of the people who stop antibiotics mid-way from fever, and a decline in the apparent symptoms (Saeed et al. 2020).

Table 5. Phenotype of MDR Staphylococcus aureus and S. epidermidis

\begin{tabular}{lll}
\hline Type of strains & $\mathbf{n}(\%)$ & Phenotype of bacteria MDR \\
\hline $\begin{array}{l}\text { Staphylococcus epidermidis } \\
(\mathrm{n}=22)\end{array}$ & $1(4.5 \%)$ & CIP, GEN, SXT, ERY, LIN, PRI, FOS \\
& $1(4.5 \%)$ & FOX, OXA, GEN, SXT, ERY, LIN, SPI, PRI, FOS \\
& $2(9.5 \%)$ & FOX, OXA, CIP, GEN, SXT, ERY, SPI, PRI, FOS \\
& $2(9.1 \%)$ & FOX, OXA, CIP, GEN \\
& $1(4.5 \%)$ & FOX, OXA, SXT, ERY \\
$1(4.5 \%)$ & FOX, OXA, GEN, ERY, LIN, SPI, FOS \\
$1(4.5 \%)$ & FOX, OXA, CIP, GEN, SXT, ERY \\
$1(4.5 \%)$ & SXT, ERY, LIN, SPI, PRI, FOS \\
$2(9.1 \%)$ & FOX, OXA, SXT, ERY, LIN, SPI \\
$1(4.5 \%)$ & FOX, OXA, CIP, SXT, ERY, PRI \\
$2(9.1 \%)$ & FOX, OXA, CIP, GEN, SXT, ERY, LIN, PRI, FOS \\
$1(4.5 \%)$ & FOX, OXA, GEN, SXT, LIN \\
Staphylococcus aureus $(\mathrm{n}=6)$ & $2(9.1 \%)$ & FOX, OXA, SXT, ERY, LIN, SPI \\
& $1(4.5 \%)$ & FOX, OXA, CIP, GEN, SXT, ERY, LIN, PRI, FOS \\
& $1(4.5 \%)$ & LIN, SPI, FOS \\
& $1(16.7 \%)$ & FOX, OXA, IMP, CIP, SXT, ERY, LIN, SPI, PRI, FOS \\
$1(16.7 \%)$ & FOX, OXA, SXT, ERY, LIN, SPI, PRI, FOS \\
$1(16.7 \%)$ & FOX, OXA, CIP, GEN, SXT, LIN \\
\hline
\end{tabular}


Table 6: Strains MDR to several of families of antibiotics

\begin{tabular}{|c|c|c|c|c|c|c|c|c|c|c|c|c|}
\hline \multirow{3}{*}{ Strains } & \multicolumn{12}{|c|}{ Number $(n)$ and percentage $(\%)$ of isolates MDR to several families } \\
\hline & \multicolumn{2}{|c|}{ Three } & \multicolumn{2}{|c|}{ Four } & \multicolumn{2}{|c|}{ Five } & \multicolumn{2}{|c|}{ Six } & \multicolumn{2}{|c|}{ Seven } & \multicolumn{2}{|c|}{ Eight } \\
\hline & $\mathbf{n}$ & $\%$ & $\mathbf{n}$ & $\%$ & $\mathbf{n}$ & $\%$ & $\mathbf{n}$ & $\%$ & $\mathbf{n}$ & $\%$ & $\mathbf{n}$ & $\%$ \\
\hline S. aureus $(\mathrm{n}=43)$ & 2 & 33.3 & 0 & 0 & 1 & 16.7 & 1 & 16.7 & 2 & 33.3 & 0 & 0 \\
\hline S. epidermidis $(\mathrm{n}=59)$ & 6 & 27.3 & 0 & 0 & 9 & 40.9 & 0 & 0 & 5 & 22.7 & 2 & 9.1 \\
\hline
\end{tabular}

Table 7. resistance to methicillin and multi-drug resistance profile of $S$. aureus and S. epidermidis according to samples types

\begin{tabular}{lcccc}
\hline \multirow{2}{*}{ Samples } & \multicolumn{2}{c}{ S. aureus } & \multicolumn{2}{c}{ S. epidermidis } \\
\cline { 2 - 5 } & MRSA & MDR & R to meth & $13(59.1 \%)$ \\
Urine & $1(9.1 \%)$ & $1(16.7 \%)$ & $14(56 \%)$ & $1(4.5 \%)$ \\
Skin & $0(0 \%)$ & $0(0 \%)$ & $1(4 \%)$ & $1(4.5 \%)$ \\
Vaginal & $0(0 \%)$ & $0(0 \%)$ & $1(4 \%)$ & $5(22.7 \%)$ \\
Pus & $7(63.6 \%)$ & $4(66.7 \%)$ & $5(20 \%)$ & $1(4.5 \%)$ \\
Mammary & $2(18.2 \%)$ & $1(16.7 \%)$ & $2(8 \%)$ & $1(4.5 \%)$ \\
Spermculture & $1(9.1 \%)$ & $0(0 \%)$ & $0(8 \%)$ & $0(0 \%)$ \\
Blood & $0(0 \%)$ & $0(0 \%)$ & $0(0 \%)$ & $0(0 \%)$ \\
Vulvar & $0(0 \%)$ & $6(13.9 \%)$ & $25(42.4 \%)$ & $22(37.3 \%)$ \\
Total & $11(25.6 \%)$ & & &
\end{tabular}

Results show that the rate of MDR and MR in $S$. epidermidis is higher than found among $S$. aureus, according to Cercenado (2010) and Morgenstern et al. (2016) most MR-CoNs isolates were multi-drug resistant, and that the rate of antibiotic resistance of CoNs isolated from different clinical infections is generally higher than CoPs-related infections. Thus, treatment of methicillinresistant CoNs related infections is difficult to challenge (Biavasco et al. 2000).

From pus, the prevalence of MDR and Methicillin Resistance (MR) among S. aureus is to $(66.7 \% ; 63.6 \%)$ respectively, these rates are higher than that observed in $S$. epidermidis. However, from urine the antibiotic resistance of $S$. epidermidis is higher than that shown among $S$. aureus (Table 7), according to Muder et al. (2006) which indicate that $S$. aureus is a rare cause of urinary tract infections, accounting for only $0.5 \%$ to $6 \%$ of all positive urine cultures.

The present study determines the phenotypic analysis of antibiotic resistance of $43 \mathrm{~S}$. aureus and $59 \mathrm{~S}$. epidermidis strains isolated from human community infections samples in Oum El Bouaghi city (Algeria) and it indicates that $S$. epidermidis is more prevalent in community infection than $S$. aureus with high levels of resistance to commonly used antibacterials except for vancomycin. The presence of MDR in some $S$. epidermidis and $S$. aureus strains is due to the misuse of antibiotics in Algeria and should be considered as a serious health concern. In Algeria, regular surveillance of antibiotic prescriptions for human infections is essential in order to conserve the efficacy of the antibiotics and reduce the emergence of multi-drug resistant strains.

\section{ACKNOWLEDGEMENTS}

The authors would like to thank the Directorate General for Scientific Research and Technological Development (DGRSDT) of Algeria.

\section{REFERENCES}

Abdeen EE, Mousa WS, Abdelsalam SY, Heikal HS, Shawish RR, Nooruzzaman M, Soliman MM, Batiha GE, Hamad A, Abdeen A. 2021. Prevalence and characterization of coagulase-positive Staphylococci from food products and human specimens in Egypt. Antibiotics 10 (1): 75. DOI: 10.3390/antibiotics10010075.

Achek R, Hotzel H, Cantekin Z, Nabi I, Hamdi TM, Neubauer H, El-Adawy H. 2018. Emerging of antimicrobial resistance in staphylococci isolated from clinical and food samples in Algeria. BMC Res Notes 11: 663. DOI: 10.1186/s13104-018-3762-2.

Alioua M, Labid A, Amoura K, Bertine M, Gacemi-Kirane D, Dekhil M. 2014. Emergence of the European ST80 clone of communityassociated methicillin-resistant Staphylococcus aureus as a cause of healthcare-associated infections in Eastern Algeria. Médecine et Maladies Infectieuses 44: 180-183. DOI: 10.1016/j.medmal.2014.01.006.

Altaf M, Ijaz M, Iqbal MK, Rehman A, Avais M, Ghaffar A, Ayyub RM. 2019. Molecular characterization of Methicillin-Resistant Staphylococcus aureus (MRSA) and associated risk factors with the occurrence of goat mastitis. Pak Vet J 40 (1): 1-6. DOI: $10.29261 /$ pakvetj/2019.079

Antri K, Rouzic N, Dauwalder O, Boubekri I, Bes M, Lina G, Vandenesch F, Tazir M, Ramdani-Bouguessa N, Etienne J. 2011. High prevalence of methicillin-resistant Staphylococcus aureus clone ST80-IV in hospital and community settings in Algiers. Clin Microbiol Infect 17: 526-532. DOI: 10.1111/j.1469-0691.2010.03273.x.

Archana Iyer, Taha Kumosani, Esam Azhar, Elie Barbour, Steve Harakeh. 2014. High incidence rate of methicillin-resistant Staphylococcus aureus (MRSA) among healthcare workers in Saudi Arabia. J Infect Dev Ctries 8 (3): 372-378. DOI: 10.3855/jidc.3589.

Asante Jonathan, Daniel GA, Akebe LKA, Anou MS, Usha G, Linda AB, and Sabiha YE. 2020. Review of Clinically and Epidemiologically Relevant Coagulase-Negative Staphylococci in Africa. Microb Drug Resist 26 (8): 951-970. DOI: 10.1089/mdr.2019.0381.

Bassetti M, Poulakou G, Ruppe E, Bouza E, Van Hal SJ, Brink A. 2017. Antimicrobial resistance in the next 30 years, humankind, bugs and drugs: a visionary approach. Intensive Care Med 43: 1464-1475. DOI: 10.1007/s00134-017-4878-x.

Becker K, Heilmann C, Peters G. 2014. Coagulase-negative Staphylococci. Clin Microbiol Rev 27: 870-926. DOI: 10.1128/CMR.00109-13.

Benouda A, Elhamzaui S. 2009. Staphylococcus aureus : épidémiologie et prévalence des souches résistantes à la methicilline (SARM) au Maroc. Revue Tunisienne d'Infectiologie 3 (8) : 15-20.

Benyagoub E, Benyagoub E, Berbaoui H, Rahmani C, Benyoussef L. 2020. Identification and study of the emergence of antibiotic 
resistance of microorganisms responsible for urinary tract infections in Bechar (Algeria). Bangladesh J Med Sci 19 (03): 404-413. DOI: 10.3329/bjms.v19i3.45856.

Biavasco F, Vignaroli C, Varaldo PE. 2000. Glycopeptide resistance in coagulase-negative Staphylococci. Eur J Clin Microbiol Infect Dis 19 403-417. DOI: 10.1007/s100960000299.

Castro A, C Santos, H Meireles, Silva J, and Teixeira P. 2016. Food handlers as potential sources of dissemination of virulent strains of Staphylococcus aureus in the community. J Infect Publ Health 9: 153160. DOI: 10.1016/j.jiph.2015.08.001.

Ceballos S, Aspiroz C, Ruiz-Ripa L, Reynaga E, Azcona-Gutiérrez JM, Rezusta A, Seral C, Antoñanzas F, Torres L, López C, López-Cerero L, Cercenado E, Zarazaga M, Torres C. 2019. Study Group of clinical LA-MRSA epidemiology of methicillin-resistant Staphylococcus aureus in hospitals located in Spanish regions with different pig farming densities: a multicentre study. J Antimicrob Chemother 74: 2157-2161. DOI: $10.1093 / \mathrm{jac} / \mathrm{dkz} 180$.

Cercenado E. 2010. Update of antimicrobial resistance in Gram-positive microorganisms. Med Clin Suppl 3: 10-15.

Chabi R, Momtaz H. 2019. Virulence factors and antibiotic resistance properties of the Staphylococcus epidermidis strains isolated from hospital infections in Ahvaz, Iran. Trop Med Health 47: 56. DOI: 10.1186/s41182-019-0180-7.

Chijioke A, Vivian NN, Christian UO. 2016. Prevalence and antibiotic susceptibility pattern of Staphylococcus aureus isolated from various clinical specimens in southeast Nigeria. MO J Cell Sci Rep 3 (2): 6063. DOI: 10.15406/mojcsr.2016.03.00054.

Contreras A, Luengo C, Sanchez A, Corrales JC. 2003. The role of intramammary pathogens in dairy goats. Livest Prod Sci 79 (2-3): 273-283. DOI: 10.1016/S0301-6226(02)00172-0.

Dubin DT, Fitzgibbon JE, Nahvi MD, John JF. 1999. Topoisomerases sequences of coagulase-negative staphylococcal isolates resistant to ciprofloxacin or trovafloxacin. Antimicrob Agents Chemother 43: 1631-1637. DOI: 10.1128/AAC.43.7.1631

Duran N, Ozer B, Duran GG, Onlen Y, Demir C. 2012. Antibiotic resistance genes and susceptibility patterns in staphylococci. Indian $\mathbf{J}$ Med Res 135 (3): 389-396.

Eladli MG, Alharbi NS, Khaled JM, Kadaikunnan S, Alobaidi AS Alyahya SA. 2019. Antibiotic-resistant Staphylococcus epidermidis isolated from patients and healthy students comparing with antibioticresistant bacteria isolated from pasteurized milk. Saudi J Biol Sci 26: 1285-1290. DOI: 10.1016/j.sjbs.2018.05.008.

Fišarová L, Pantůček R, Botka T, Doškař J. 2019. Variability of resistance plasmids in coagulase-negative staphylococci and their importance as a reservoir of antimicrobial resistance. Res Microbiol 170: 105-111. DOI: 10.1016/j.resmic.2018.11.004.

Frédéric J, Elvire MK, Mérens A, Cavallo JD. 2008. Les difficultés d'interprétation de l'examen cytobactériologique des urines. Revue Francophone des Laboratoires 38: 51-59. DOI: 10.1016/S1773035X(08)74525-8.

Gahamanyi N, Bitariho B, Muhire V. 2017. Prevalence of Staphylococcus aureus among clinical isolates and their responses to selected antibiotics at Centre Hospitalier Universitaire de Kigali (CHUK). J Microbiol Exp 5 (4): 00158. DOI: 10.15406/jmen.2017.05.00158.

Holmes RL, Jorgensen H. 2008. Inhibitory activities of 11 antimicrobial agents and bactericidal activities of vancomycin and daptomycin against invasive methicillin-resistant Staphylococcus aureus isolates obtained from 1999 through 2006. Antimicrob Agents Chemother 52: 757-760. DOI: 10.1128/AAC.00945-07.

Ji G, Chen Q, Gong X, Zheng F, Li S, Liu Y. 2018. Topoisomerase mutations are associated with high-level ciprofloxacin resistance in Staphylococcus saprophyticus, Enterococcus faecalis and Escherichia coli isolated from ducks. Pak Vet J 38: 39-45. DOI: 10.29261/pakvetj/2018.008.

Johler S, Layer F, Stephan R. 2011. Comparison of virulence and antibiotic resistance genes of food poisoning outbreak isolates of Staphylococcus aureus with isolates obtained from bovine mastitis milk and pig carcasses. J Food Prot 74 (11): 1852-1859. DOI: 10.4315/0362-028X.JFP-11-192.

John J, George S, Nori SRC, and Nelson-Sathi S. 2019. Phylogenomic analysis reveals the evolutionary route of resistant genes in Staphylococcus aureus. Genome Biol Evol 11 (10): 2917-2926. DOI: 10.1093/gbe/evz213.

Kaasch AJ, Barlow G, Edgeworth JD, Fowler VG Jr, Hellmich M, Hopkins S, Kern WV, Llewelyn MJ, Rieg S, Rodriguez-Baño J, Scarborough M, Seifert H, Soriano A, Tilley R, Tőrők ME, Weiß V,
Wilson AP, Thwaites GE. 2014. Staphylococcus aureus bloodstream infection. J Infect 68: 242-251. DOI: 10.1016/j.jinf.2013.10.015.

Kakai R, Wamola IA. 2002. Minimising antibiotic resistance to Staphylococcus aureus in developing countries East. Afr Med J 79: 574-579. DOI: 10.4314/eamj.v79i11.8801.

Kandi V. 2018. Coral dermatitis or infectious dermatitis: Report of a case of Staphylococcus aureus infection of skin after scuba diving. Cureus 10 (2): e2196. DOI: 10.7759/cureus.2196.

Kellie J, Goodlet, Fatima Z, Benhalima, Michael D, Nailor. 2019. A systematic review of single-dose aminoglycoside therapy for urinary tract infection: Is it time to resurrect an old strategy? Antimicrob Agents Chemother 63 (1): e02165-18. DOI: 10.1128/AAC.02165-18.

Li B, Webster TJ. 2018. Bacteria antibiotic resistance: New challenges and opportunities for implant 385 associated orthopedic infections. J Orthop Res 36: 22-32.

Longauerova A. 2006. Coagulase-negative staphylococci and their participation in pathogenesis of human infections. Bratisl Lek Listy 107 (11-12): 448-452.

Mahendra P, Gemechu BK, Lencho MM, Venkataramana K. 2020. Epidemiology, pathogenicity, animal infections, antibiotic resistance, public health significance, and economic impact of Staphylococcus aureus: a comprehensive review. Am J Publ Health Res 8 (1): 14-21.

Martineau F, François JP, Nicolas L, Christian MN, Paul HR, Marc O, MICHEL GB. 2000. Correlation between the resistance genotype determined by Multiplex PCR assays and the antibiotic susceptibility patterns of Staphylococcus aureus and Staphylococcus epidermidis. Antimicrob Agents Chemother. DOI: 10.1128/AAC.44.2.231238.2000.

Massanari RM, Pfaller MA, Wakefield DS. 1988. Implication of acquired oxacillin resistance in the management and control of Staphylococcus aureus infections. J Infect Dis 158: 702-709. DOI: 10.1093/infdis/158.4.702.

Morency-Potvin P, Schwartz DN, Weinstein RA. 2017. Antimicrobial stewardship: how the microbiology laboratory can right the ship. Clin Microbiol Rev 30: 381-407. DOI: 10.1128/CMR.00066-16.

Morgenstern M, Erichsen C, Hackl S, Mily J, Militz M, Friederichs J, Hungerer S, Bühren V, Moriarty TF, Post V, Richards RG, Kates SL. 2016. Antibiotic resistance of commensal Staphylococcus aureus and coagulase-negative staphylococci in an international cohort of surgeons: A prospective point-prevalence study. PLoS One 11 (2): e0148437. DOI: 10.1371/journal.pone.0148437.

Muder RR, Brennen C, Rihs JD, Wagener MM, Obman A, Stout JE, Yu VL. 2006. Isolation of Staphylococcus aureus from the urinary tract: association of isolation with symptomatic urinary tract infection and subsequent staphylococcal bacteremia. Clin Infect Dis 42: 46-50. DOI: $10.1086 / 498518$.

Nanoukona C, Argemi X, Sogbo F, Orekanb J, Keller D, Affolabi D, Schramma F, Riegel P, Baba-Moussac L, Prévost G. 2017. Pathogenic features of clinically significant coagulase-negative Staphylococci in hospital and community infections in Benin. Intl $\mathbf{J}$ Med Microbiol 307 (1): 75-82. DOI: 10.1016/j.ijmm.2016.11.001.

Nascimento TC, da Silva VL, Ferreira-Machado AB, Diniz CG. 2015. Potential spread of multidrug-resistant coagulase-negative Staphylococci through healthcare waste. J Infect Dev Ctries 9 (1): 029-034. DOI: 10.3855/jidc.4563.

Nemeghaire S, Argudı'n MA, Feßler AT, Hauschild T, Schwarz S, Butaye P. 2014. The ecological importance of the Staphylococcus sciuri species group as a reservoir for resistance and virulence genes. Vet Microbiol. DOI:10.1093/jac/dku268.

Oliveira WF, Silva PM, Silva RC, Silva GM, Machado G, Coelho LC, Correia MT. 2017. Staphylococcus aureus and Staphylococcus epidermidis infections on implants. J Hosp Infect 98 (2): 111-117. DOI: 10.1016/j.jhin.2017.11.008.

Onemu OS and Ophori EA. 2013. Prevalence of Multi-Drug Resistant Staphylococcus aureus in clinical specimens obtained from patients attending the University of Benin Teaching Hospital, Benin City, Nigeria. J Nat Sci Res 3 (5): 154-159.

Otto M. 2009. Staphylococcus epidermidis -the 'accidental pathogen'. Nat Rev Microbiol 7 (8): 555-567. DOI: 10.1038/nrmicro2182.

Quinn PJ, Carter ME, Markey BK, Carter GR. 1994. Clinical veterinary microbiology. 5th eds. Elsevier, Philadelphia, PA.

Rogers KL, Fey PD, Rupp ME. 2009. Coagulase-negative staphylococcal infections. Infect Dis Clin North Am 23: 73-98. DOI: 10.1016/j.idc.2008.10.001.

Saeed A, Ahsan F, Nawaz M, Iqbal K, Ur Rehman K, Ijaz T. 2020. Incidence of vancomycin-resistant phenotype of the Methicillin- 
Resistant Staphylococcus aureus isolated from a Tertiary Care Hospital in Lahore. Antibiotics 9 (1): 3. DOI 10.3390/antibiotics9010003.

Safarpoor D, Gandomi F, Basti H, Misaghi AA, Rahimi E. 2017. Phenotypic and genotypic characterization of antibiotic resistance of methicillin-resistant Staphylococcus aureus isolated from hospital food. Antimicrob Resist Infect Control 6: 1-11. DOI: 10.1186/s13756-017-0257-1.

Saleem N, Nawaz M, Ghafoor A, Javeed A, Mustafa A, Yousuf MR, Khan I. 2018. Phenotypic and molecular analysis of antibiotic resistance in Lactobacilli of poultry origin from Lahore, Pakistan. Pak Vet J 38 (4): 409-413. DOI: 10.29261/pakvetj/2018.084.

Sangita T, Lokendra BS. 2019. Changing trend of neonatal septicemia and antibiotic susceptibility pattern of isolates in Nepal. Int J Pediatr. DOI: $10.1155 / 2019 / 3784529$.

Schwarz S, Feßler AT, Loncaric I, Wu C, Kadlec K, Wang Y, Shen J. 2018. Antimicrobial resistance among staphylococci of animal origin. Microbiol Spectrum 6 (4): ARBA-0010-2017. DOI: 10.1128/microbiolspec.ARBA-0010-2017.

Shittu A, Oyedara O, Abegunrin F, Okon K, Raji A, Taiwo S, Ogunsola F, Onyedibe K, Elisha G. 2012. Characterization of methicillinsusceptible and -resistant staphylococci in the clinical setting: a multicentre study in Nigeria. BMC Infect Dis 12: 286. DOI: 10.1186/1471-2334-12-286.

Siberry GK, Tekle T, Carroll K, Dick J. 2003. Failure of clindamycin treatment of methicillin-resistant Staphylococcus aureus expressing inducible clindamycin resistance in vitro. Clin Infect Dis 37: 12571260. DOI: $10.1086 / 377501$.
Srinivasan A, Dick JD, Perl TM. 2002. Vancomycin resistance in staphylococci. Clin Microbiol Rev 15: 430-438. DOI: 10.1128/CMR.15.3.430-438.2002.

Virdis S, Scarano C, Cossu F, Spanu V, Spanu C, Santis EPL. 2010. Antibiotic resistance in Staphylococcus aureus and coagulasenegative Staphylococci isolated from goats with subclinical mastitis. Vet Med Int 2010: 517060. DOI: 10.4061/2010/517060.

Wesley E, Kloos, Wolfshohl JF. 1982. Identification of Staphylococcus species with the API STAPH-IDENT system. J Clin Microbiol 16 (3): 509-516. DOI: 10.1128/JCM.16.3.509-516.1982.

Yang Q, Li X, Jia P, Giske C, Kahlmeter G, Turnidge J, Yu Y, Lv Y, Wang M, Sun Z, Lin J, Li Y, Zheng B, Hu F, Guo Y, Chen Z, Li H, Zhang G, Zhang J, Kang W, Duan S, Wang T, Jing R and Xu Y. 2020. On behalf of the Chinese Committee on Antimicrobial Susceptibility Testing (ChiCAST). Determination of norvancomycin epidemiological cut-off values (ECOFFs) for Staphylococcus aureus, Staphylococcus epidermidis, Staphylococcus haemolyticus and Staphylococcus hominis. J Antimicrob Chemother. DOI: 10.1093/jac/dkaa414.

Zatout A, Djibaoui R, Kassah-Laouar A, Benbrahim C. 2020. Coagulasenegative staphylococci in Anti-Cancer Center, Batna, Algeria: antibiotic resistance pattern, biofilm formation, and detection of mecA and icaAD genes. Afr J Clin Exp Microbiol 21 (1): 21-29. DOI: 10.4314/ajcem.v21i1.3.

Zong Z, Chunhong P, Xiaoju L. 2011. Diversity of SCCmec Elements in Methicillin-Resistant Coagulase-Negative Staphylococci Clinical Isolates. PLoS ONE 6 (5): e20191. DOI: 10.1371/journal.pone.0020191. 